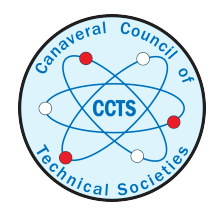

Mar 1st, 7:30 AM - 8:30 AM

\title{
Progress and Future Development toward a UAT ADS-B Transmitter for Space Operations
}

Richard Stansbury Ph.D.

Embry-Riddle Aeronautical University, stansbur@erau.edu

Follow this and additional works at: https://commons.erau.edu/space-congress-proceedings

\section{Scholarly Commons Citation}

Stansbury, Richard Ph.D., "Progress and Future Development toward a UAT ADS-B Transmitter for Space Operations" (2018). The Space Congress $®$ Proceedings. 6.

https://commons.erau.edu/space-congress-proceedings/proceedings-2018-45th/mar-1-2018/6

This Event is brought to you for free and open access by the Conferences at Scholarly Commons. It has been accepted for inclusion in The Space Congress ${ }^{\circledR}$

Proceedings by an authorized administrator of Scholarly Commons. For more information, please contact commons@erau.edu.

EMBRYRIDDLE Aeronautical University SCHOLARLY COMMONS 


\title{
Progress and Future Development toward a UAT ADS-B Transmitter for Space Operations
}

\section{Space Congress 2018}

\author{
Presenter: Richard S. Stansbury \\ College of Engineering \\ Embry-Riddle Aeronautical University, Daytona Beach, FL
}

March 1, 2018 


\section{Acknowledgements}

- NASA Flight Opportunities Program

- Up Aerospace, Inc

- Near Space Corporation

- Terminal Velocity Aerospace

- FAA Office of Commercial Space Transportation (AST) and sponsor Nickolas Demidovich

- FAA William J. Hughes Technical Center

- Chuck Greenlow and John Dinofrio

- MITRE Corporation

Resources, support and cooperation from all were vital for this opportunity to flight test the payload!

This presentation presents a work in progress funded by the FAA, but does not reflect any official views/conclusions from the sponsor. 


\section{Lecture Outline}

- Background

- ADS-B Overview

- MITRE UBR-TX

- UBR-ERAU ADS-B Payload

- Requirements

- Design and Implementation

- System Qualification

- Ground tests

- Near Space Corporation's Nano Balloon System

- Terminal Velocity Aerospace's RED-4U prototype spacecraft

- Path Forward

- Conclusion 


\section{EM=3RYRIDLE Aeronautical University}

\section{Background}

- ADS-B Overview

- MITRE UBR-TX 
- Also known as ADS-B

- Utilizes GPS position instead of Radar-based interrogation to identify location

- Additional information:

- Aircraft ID (callsign and ICAO address)

- Altitude (geodetic and/or pressure)

- Velocity

- Emergency

- Climb rate

- Quality and integrity of data
- Two standards:

- Universal Access Transceiver

- Frequency: $978 \mathrm{MHz}$

- Common for general aviation

- <17,999 ft.

- $1090 \mathrm{MHz}$ Extended Squitter (ES) Mode-S transponder

- More common for transport category aircraft

- >18,000 ft.

2020 mandate for all aircraft equipped with mode $C$ transponder to be upgraded to ADS-B out 


\section{FAA ADS-B Deployment}

- Baseline deployment of 634 radio stations is complete

- Each radio station has a minimum line-of-sight range requirement (i.e., radius) of $250 \mathrm{NM}$ based on latitude/ longitude distance (altitude is not limiting factor)

- Actual coverage may be up to 300 NM radius (currently limited by radio station software configuration)
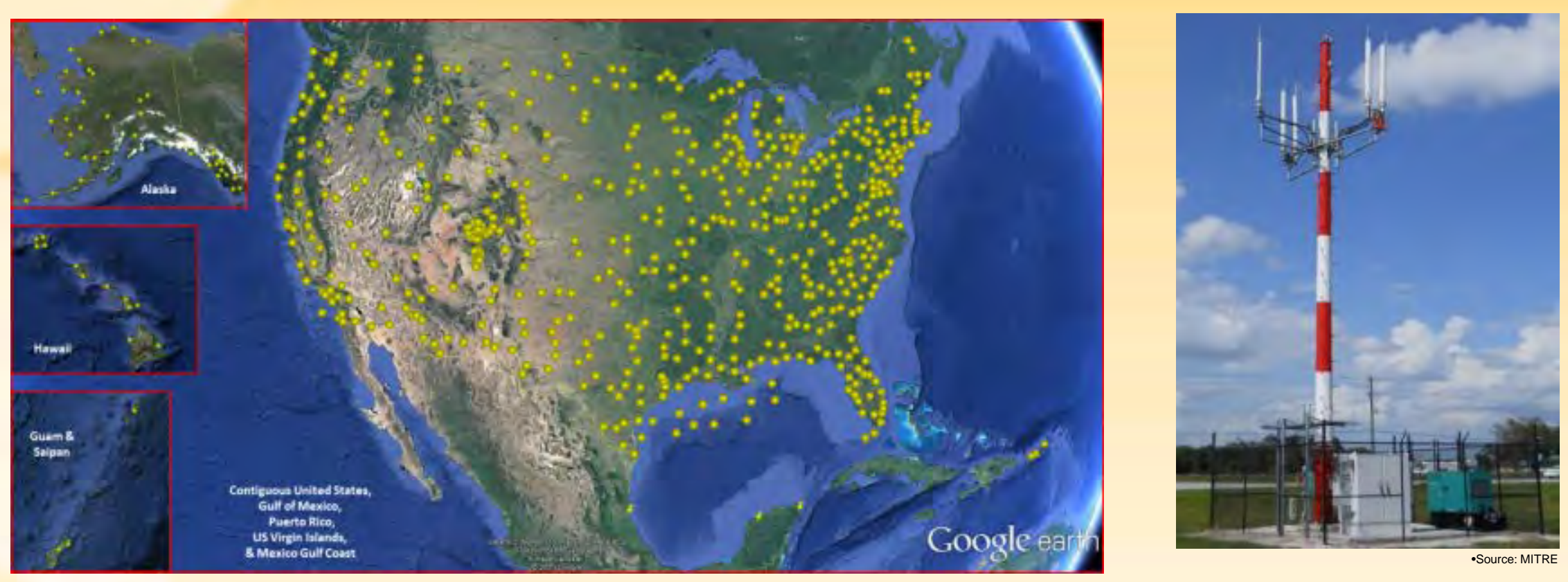

Slide courtesy of Nickolas Demidovich, FAA AST (project sponsor) 


\section{ADS-B Operations}

Aeronautical University

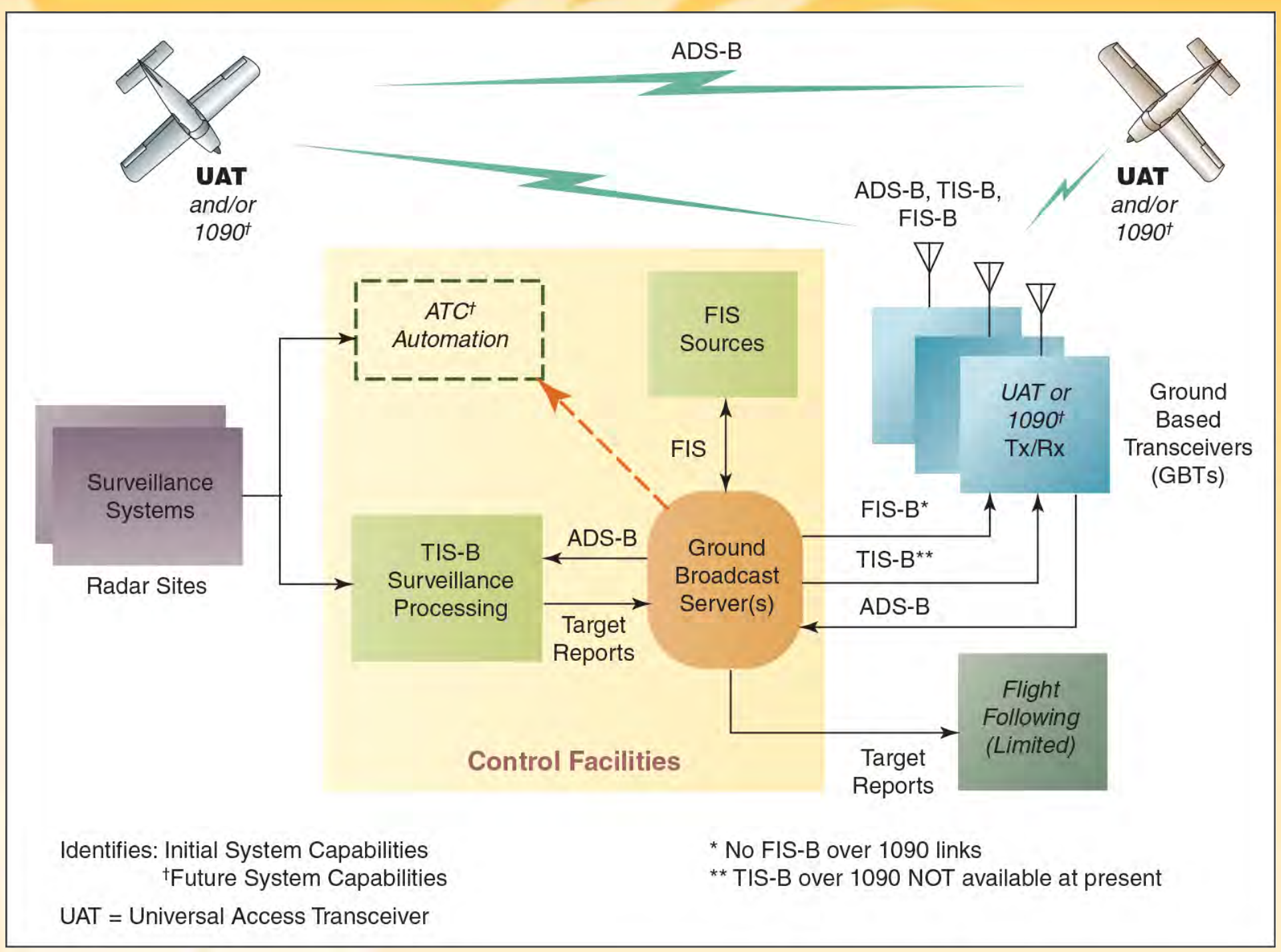

Image Source: learntoflyblog.com

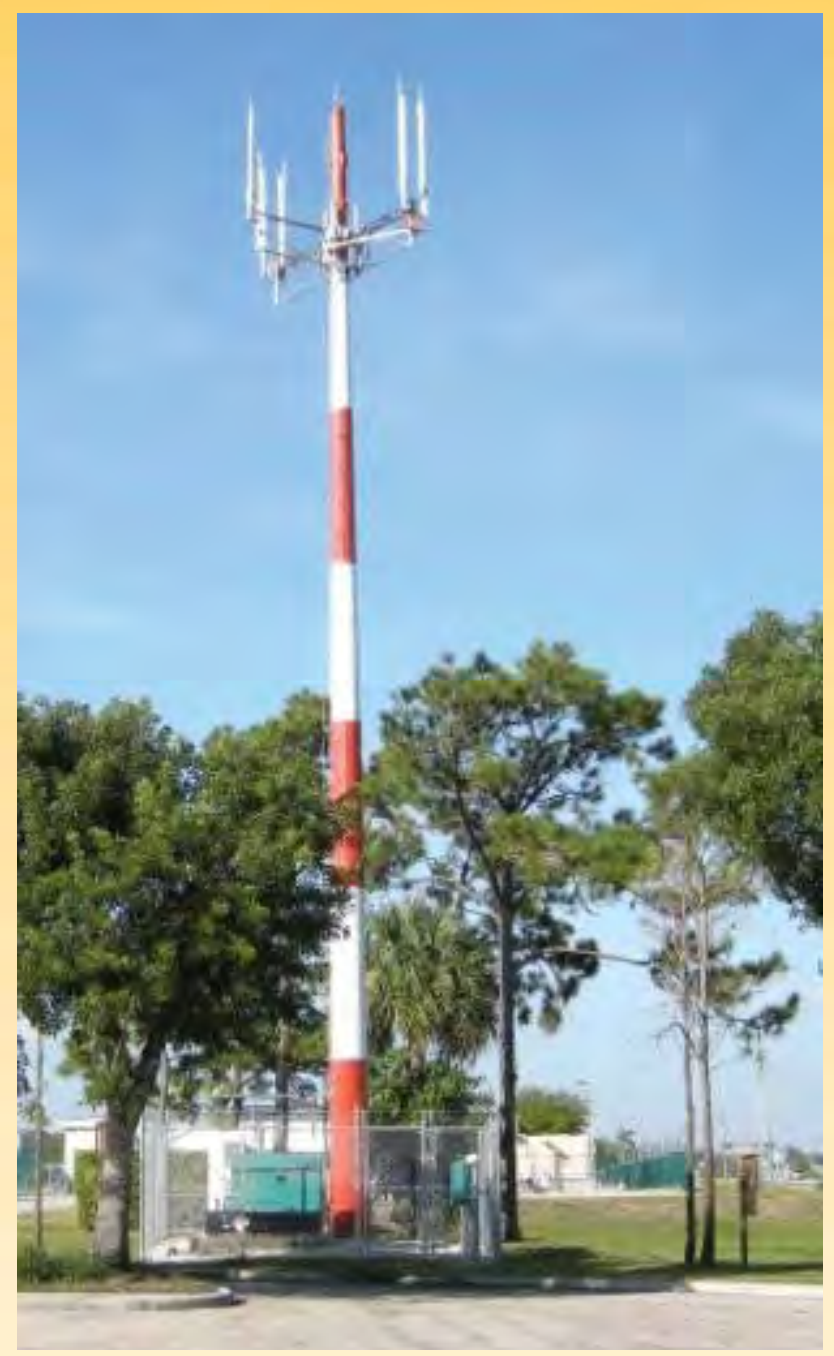

Source: Aviation Week 

Aeronautical University

2 3 4 5 6

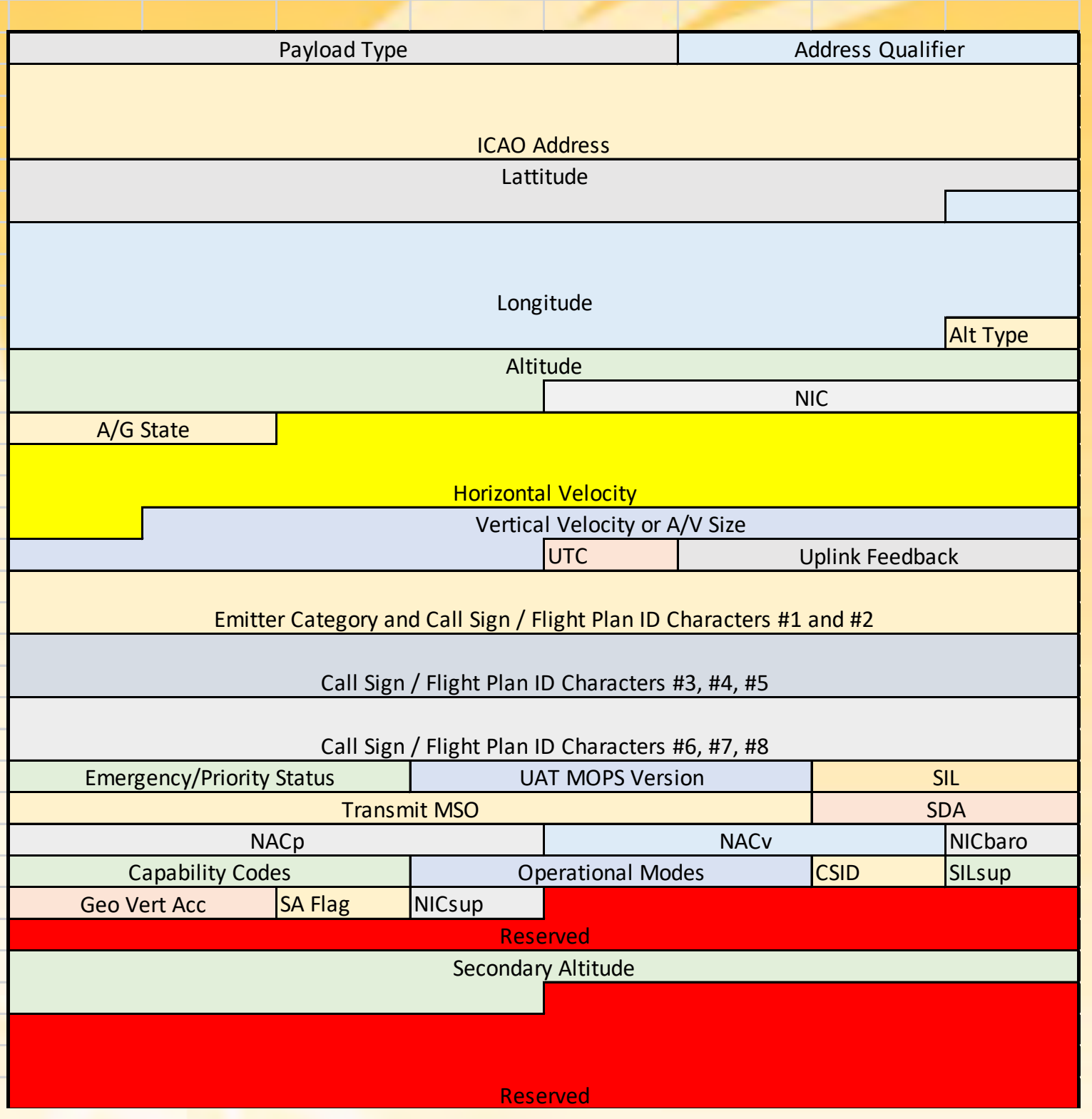

Primary and Auxiliary Message Payload shown

\section{Message Broadcast once per second}

\section{Defined in:}

RTCA DO-282B: Minimum Operational Performance Standards for Universal Access Transceiver (UAT) Automatic Dependent Surveillance - Broadcast 


\section{Purpose of Task}

- Support of suborbital reusable launch vehicles (sRLVs) for commercial space transportation requires considerations for safe integration into the national airspace system (NAS)

- ADS-B technology is used for surveillance by air traffic control and situational awareness for pilots

- This research presents the potential for adaptation of existing ADS-B technology to support operations for SRLVs operations exceeding current technology limits (primarily altitude, velocity and acceleration) 


\section{US Commercial Space Transportation}

Diversity of Vehicles and Operations

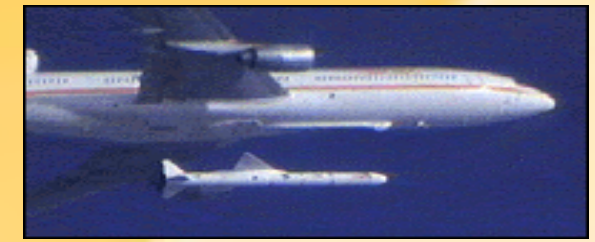

Air Launch

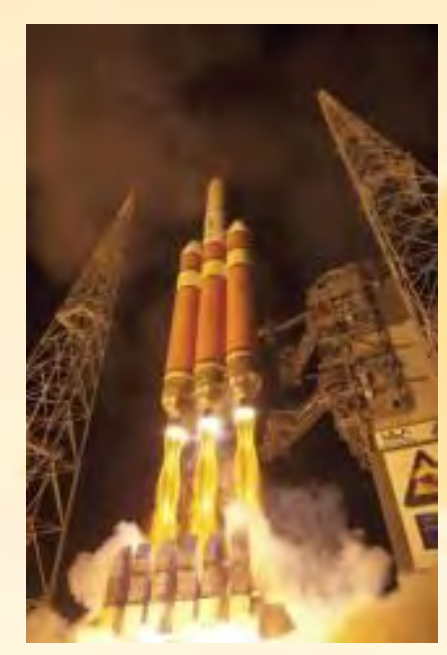

Ground Launch
Stratospheric Manned Balloons*

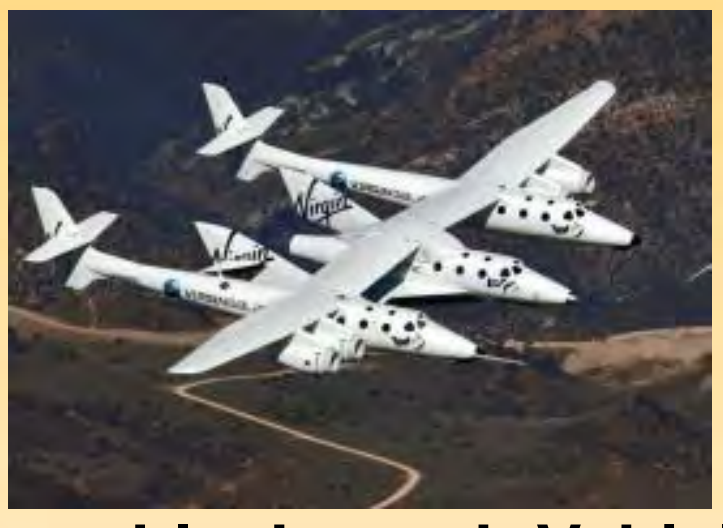

Reusable Launch Vehicles

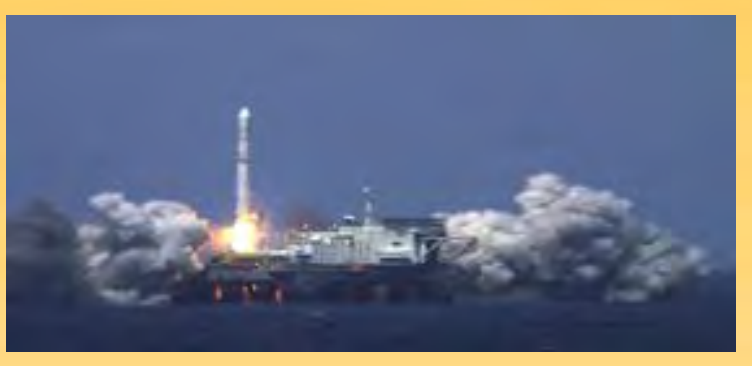

Sea Launch

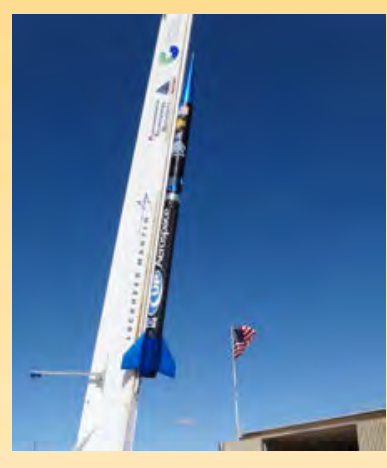

Suborbital Rockets

Over 200 licensed commercial launches safely conducted since 1987

* With Environmental Control and Life Support System (ECLSS) 


\section{Research Goals}

Enhance tracking of vehicles as they traverse through the national airspace system to mitigate the impact of commercial space operations on routine aviation operations by leveraging existing FAA infrastructure

\section{- Sub-goals:}

- Determine suitability for ADS-B for commercial space

- Determine boundary conditions of system performance

- Assess performance of prototypes on space vehicles and suitable analogues

- Identify areas of improvement in ADS-B standard to accommodate suborbital space operations

- Provide stakeholders with information regarding suitability of ADS-B as a primary or secondary tracking source 


\section{MITRE UBR-TX}

- UAT Beacon Radio - Transmit Only (UBR-TX)

- Broadcasts state vector once per second

- Supports both barometric and GPS-based altitudes

- Balloon / Rocket Flight Tests

- 2008 Red Glare V (amateur rocket)

- 2009 Red Glare VII (amateur rocket)

- 2010 AFRL research balloon

- 2010 NASA Wallops sounding rocket

- 2012 Up Aerospace Spaceloft 6

- 2012 Team America Rocket Challenge

- 2013 Up Aerospace Spaceloft 7

- 2013 Masten Xombie
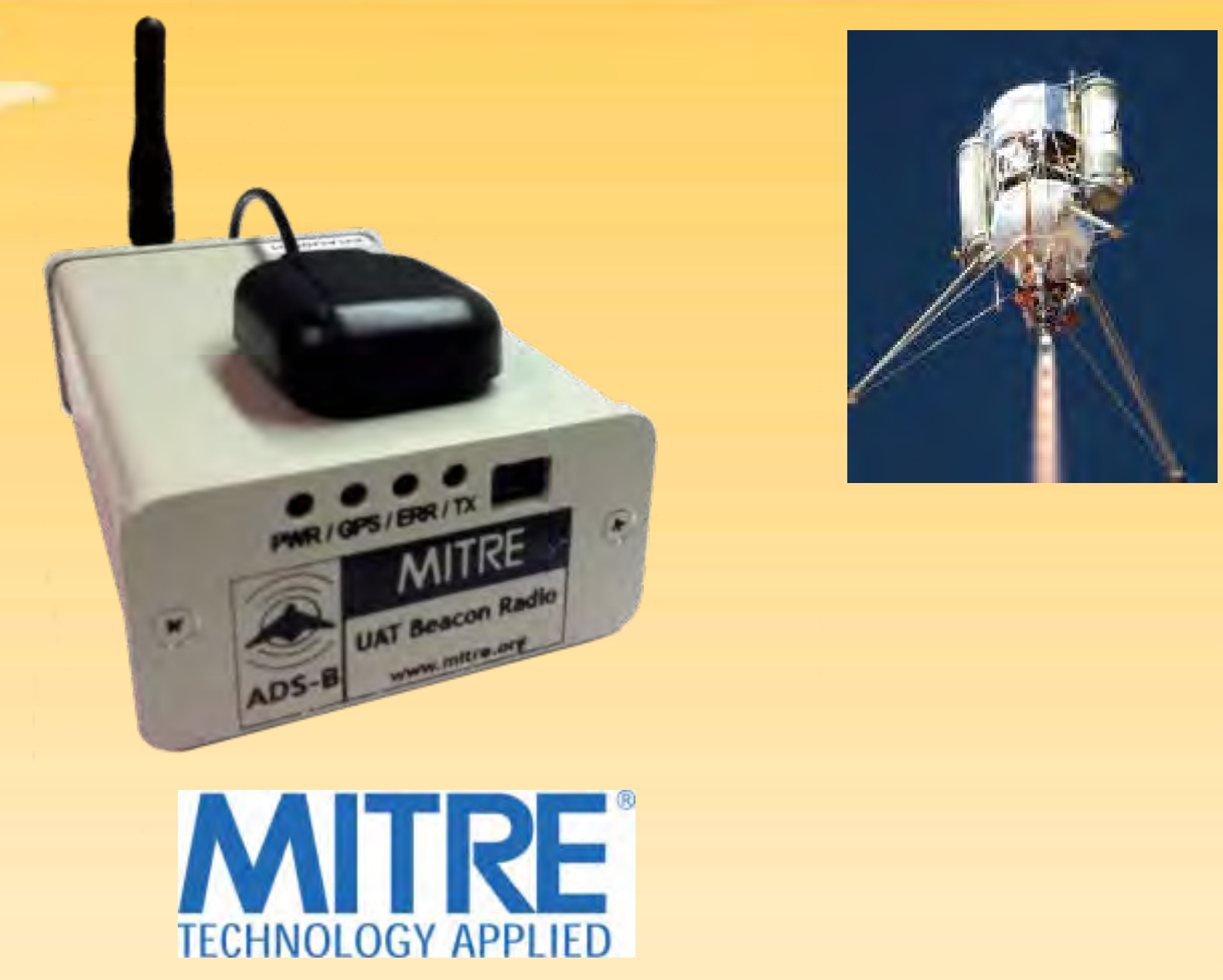

Limitations for space missions based upon altitude and velocity limits of GPS and limitations of ADS-B message, but not built for this purpose. 


\section{UBR-ERAU ADS-B Payload}

- Requirements

- Design and Implementation 


\section{High-Level Requirements}

- The enhanced ADS-B prototype shall:

- Build upon the hardware and software firmware provided by MITRE for UBR-TX payload,

- Support altitudes in excess of 60,000 ft and velocities greater than 1000 knots (i.e. in excess of COCOM/Export Control Limits),

- Address altitude limits of UAT ADS-B standard (101,337.5 ft MSL),

- Address climb rate limits of UAT ADS-B standard (roughly 320 knots), and

- Be configured to support integration onto a variety of suborbital space vehicles / space vehicle surrogates with only minimal customization.

The project team shall:

- Design and implement the enhanced UBR payload (UBR-ERAU), and

- Produce nine (9) UBR-ERAU prototypes,

- Support validation and demonstration through flight test onboard a variety of suborbital space vehicles and space vehicle surrogates. 


\section{Hardware Upgrades}

\section{EM=3RYRIDDLE Aeronautical University}

\begin{tabular}{|l|l|}
\hline Parameter & Specification \\
\hline Length & $5.75^{\prime \prime}(14.6 \mathrm{~cm})$ \\
\hline Width & $2.5^{\prime \prime}(6.35 \mathrm{~cm})$ \\
\hline Height & $2.5^{\prime \prime}(6.35 \mathrm{~cm})$ \\
\hline $\begin{array}{l}\text { Weight } \\
\text { (UBR board, daughter board, GPS, } \\
\text { battery, and enclosure) }\end{array}$ & $790 \mathrm{~g}$ \\
\hline Weight (cables, antennas, etc.) & $85-300 \mathrm{~g} \mathrm{est.}$ \\
\hline Nominal power Consumption & $110 \mathrm{~mA} @ 26$ VDC \\
\hline
\end{tabular}

\section{Hardware Upgrades}

- GPS Upgrade:

- Old GPS: SiRF GPS chipset

- New GPS: Javad TR-G2 L1 with space altitude/velocity enabled

- GPS Integration Daughter Board:

- Power regulation

- Logic conversion

\section{- UBR Board}

- Replaced components with milspec equivalents (when possible)

- UAT (978 MHz) Antennas:

- Balloon: omnidirectional monopole antenna aimed nadir (Antcom)

- Rocket: blade antenna (UB Corp)

- Window placed: patch (Antcom)

- Ruggedization:

- New enclosure

- Epoxy

- Neoprene

- Ecosorb EMI/RFI 


\section{UBR-ERAU Hardware}
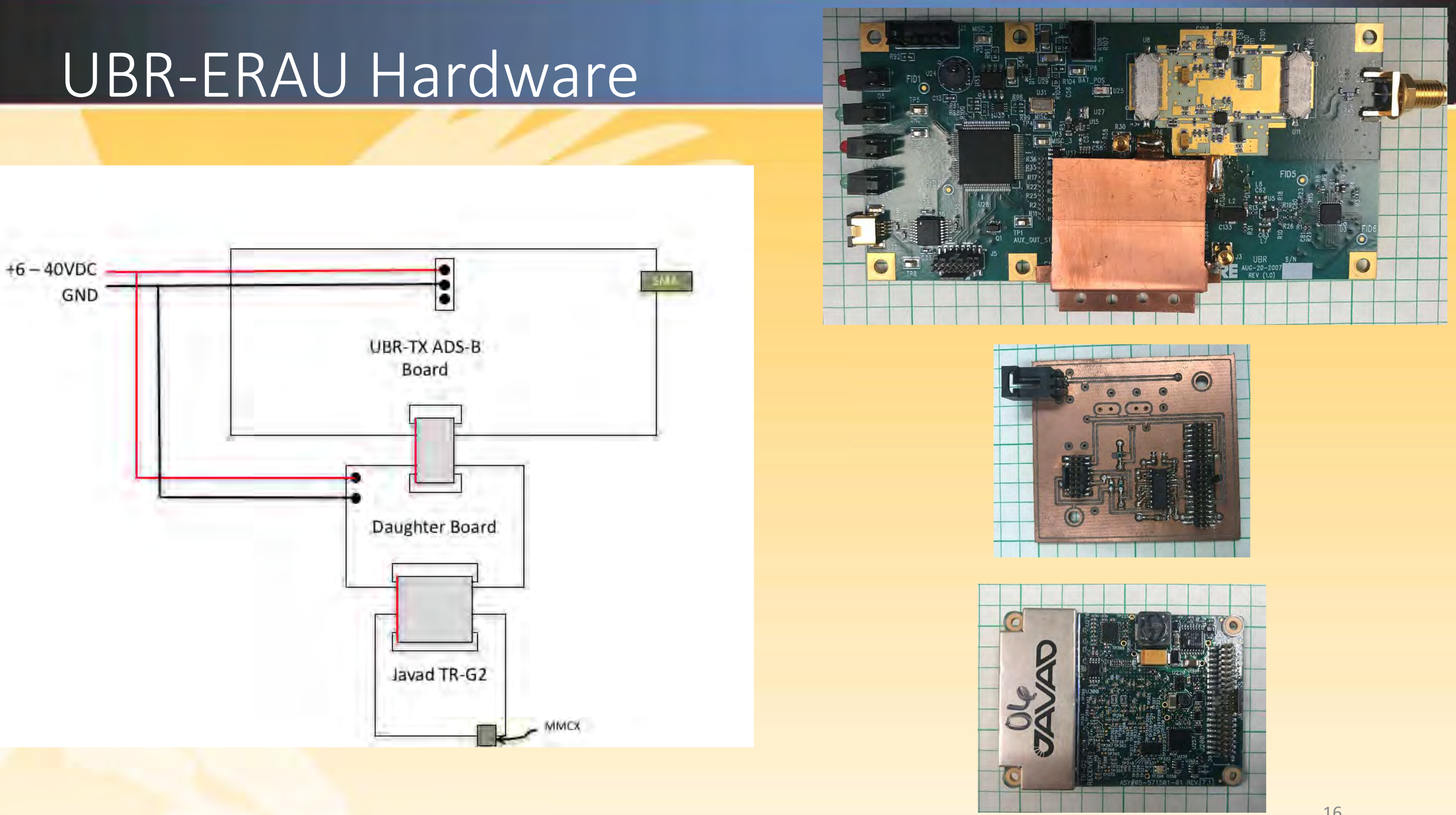


\section{UBR-ERAU Enclosure}

\section{EMBRYAIDDLE Aeronautical University}
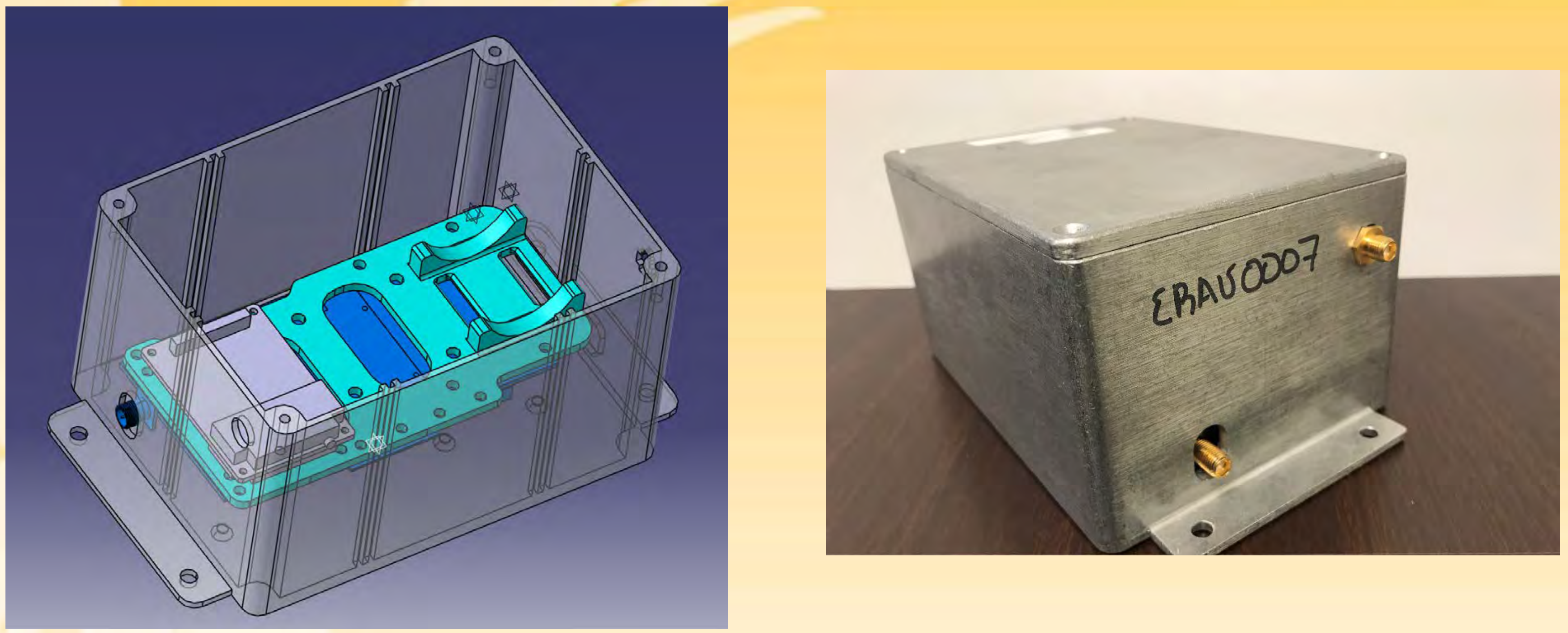


\section{Software Upgrades}

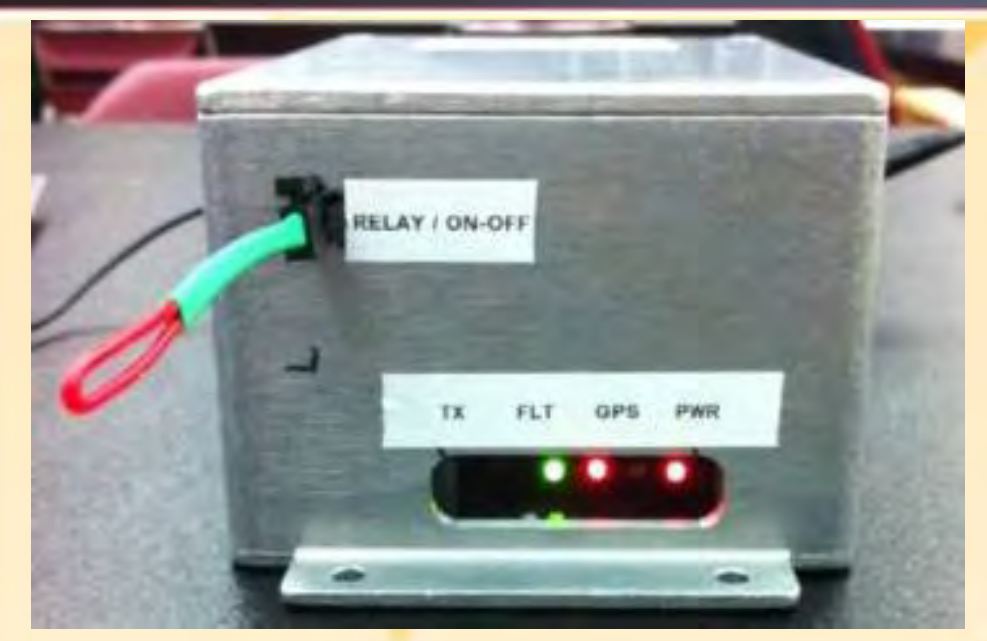

\section{Software Upgrades}

- Reuse of MITRE developed software:

- Message assembly

- Transmission of message

- GPS Parser:

- Old: SiRF binary protocol

- New: Javad GREIS binary protocol

\begin{tabular}{|l|l|}
\hline Parameter & Specification \\
\hline Length & $5.75^{\prime \prime}(14.6 \mathrm{~cm})$ \\
\hline Width & $2.5^{\prime \prime}(6.35 \mathrm{~cm})$ \\
\hline Height & $2.5^{\prime \prime}(6.35 \mathrm{~cm})$ \\
\hline $\begin{array}{l}\text { Weight } \\
\text { (UBR board, daughter board, GPS, } \\
\text { battery, and enclosure) }\end{array}$ & $790 \mathrm{~g}$ \\
\hline Weight (cables, antennas, etc.) & $85-300 \mathrm{~g}$ est. \\
\hline Nominal power Consumption & $110 \mathrm{~mA} @ 26 \mathrm{VDC}$ \\
\hline Nominal battery capacity & $7.75 \mathrm{Ah}$ \\
\hline
\end{tabular}

- Addressing maximum altitude and climb rate limits of UAT message format:

- Implemented "roll-over" over feature wherein modulo of value with limit is used

- Temporary solution to permit continued use of GBT network

- Provided general debugging of legacy code 


\section{EM=3RYRIDDLE Aeronautical University}

\section{System Qualification}

- Near Space Corporation's Nano Balloon System

- Up Aerospace SpaceLoft XL

- Terminal Velocity Aerospace RED4U Prototype Spacecraft 


\section{Technology maturation plan}

- System tested at WJH Technical Center for verification and validation using GNSS simulator on high-altitude balloon and rocket flight path simulations

- Verification of valid ADS-B message reflecting current state of simulated trajectory

- Project goal to demonstrate viability and test functional envelope of experimental ADS-B payload for sub-orbital commercial space operations

- TRL-7, proven within its operational environment

- Initial flights are summarized within this presentation

- Additional flights needed before transition to TRL-8 (i.e. move out of prototype phase)

- Diversity of new vehicles is desirable to get operator feedback 


\section{NSC NBS Balloon Flight}

Provider: Near Space Corporation

Vehicle: Nano Balloon System (NBS)

Flown under NASA Flight Opportunities Program

\section{Milestones:}

- Flights funded under NASA Flight Opportunities Program AFO1 and AFO5

- Near Space Corporation Nano Balloon System (NBS), 22 Jan 2013

- Achieved altitude near 59,000 ft

- NSC NBS Flight \#2, 15 Feb 2013

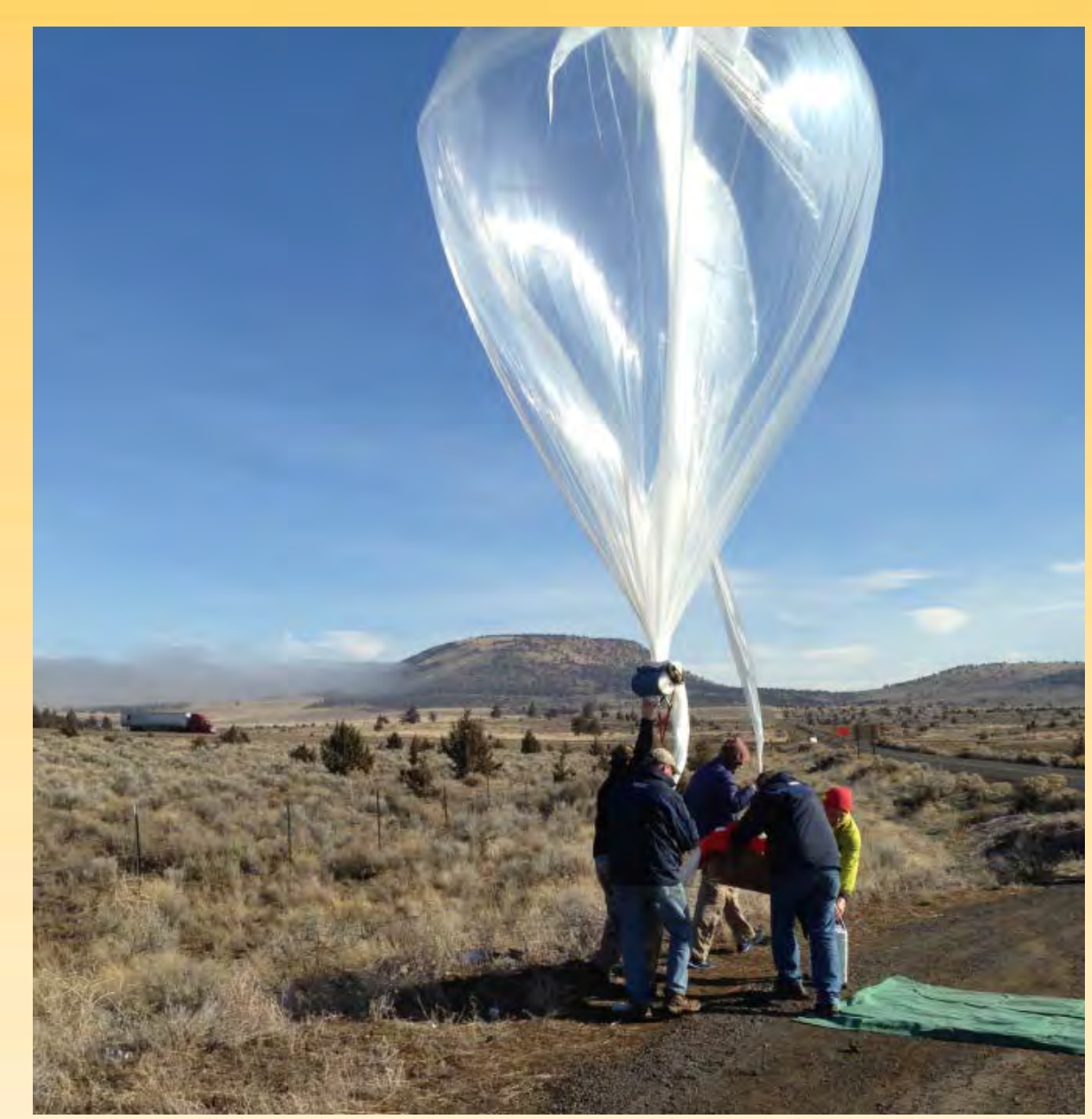

- Achieved altitude near $94,000 \mathrm{ft}$ 


\section{NSC NBS Payload Integration}

Aeronautical University
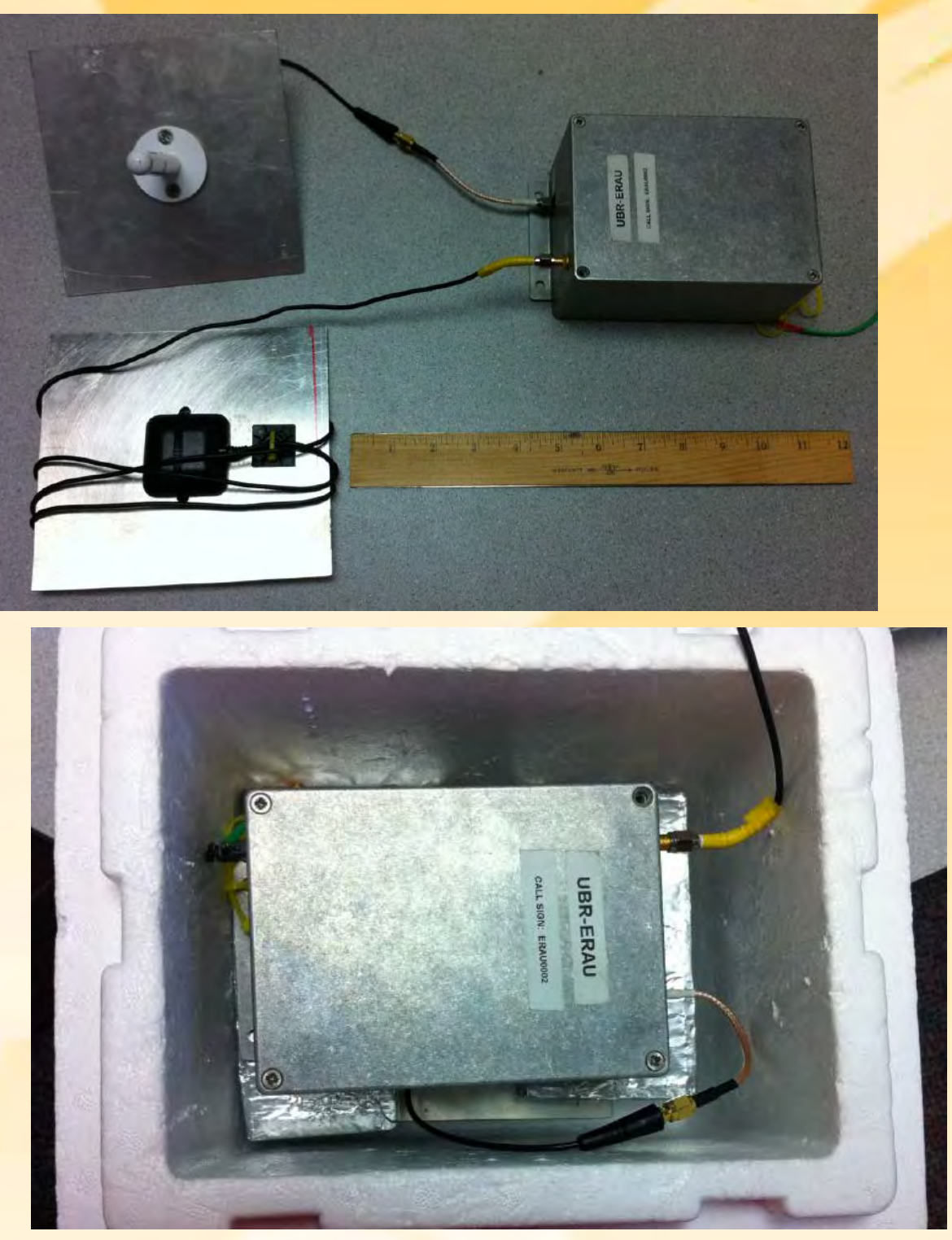

- Foam enclosure houses payload for NBS

- Internal power via onboard batteries

- Netting material used to secure payload enclosure to balloon and its telemetry unit

- Cable from NBS telemetry unit routed to payload for remote enable/disable capability

- Telemetry unit also provides position, altitude, and pressure data 


\section{NSC NBS Flight Details}

\section{Flight: 15 February 2013}

\begin{tabular}{|c|c|}
\hline \multicolumn{2}{|l|}{ Maximum Altitude } \\
\hline Geometric, MSL & $94,025 \mathrm{ft}$. \\
\hline Pressure, MSL & $94,200 \mathrm{ft}$. \\
\hline \multicolumn{2}{|l|}{ Flight Time } \\
\hline Ascent & $116 \min$ \\
\hline Float & $58 \mathrm{~min}$ \\
\hline Descent & $38 \mathrm{~min}$ \\
\hline Total & $212 \min$ \\
\hline \multicolumn{2}{|l|}{ Tracking } \\
\hline Total Number of Unique GBTs Receiving Data & 31 (available in post-processing) \\
\hline Number of GBTs Receiving at Float & 11 (available in post-processing) \\
\hline
\end{tabular}




\section{NBS Flight Path (reported by ADS-B)}
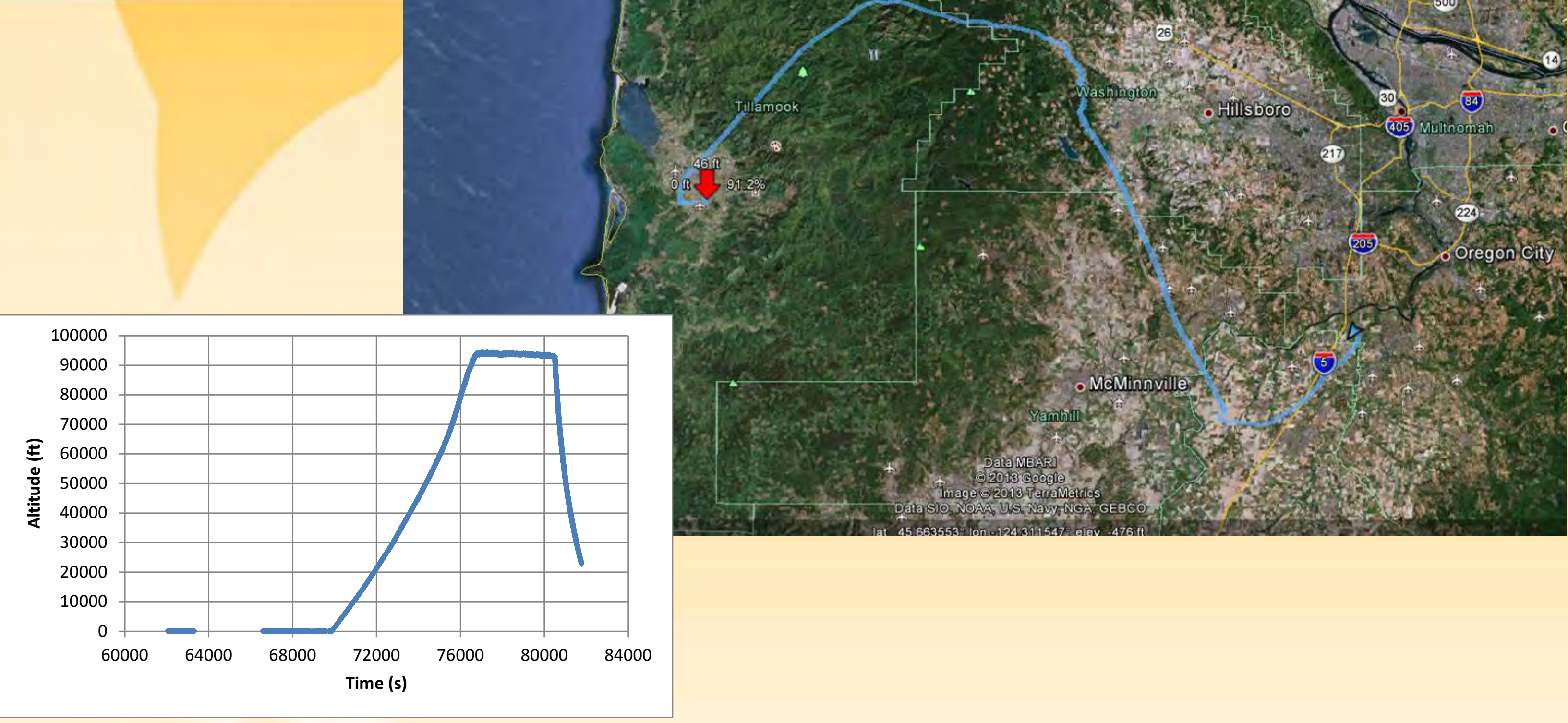

costistis

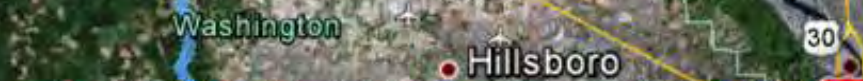

(217) 19

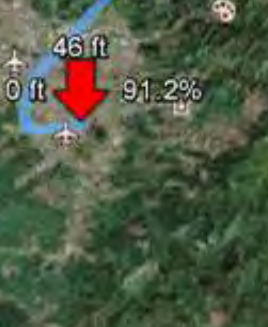

5250 .

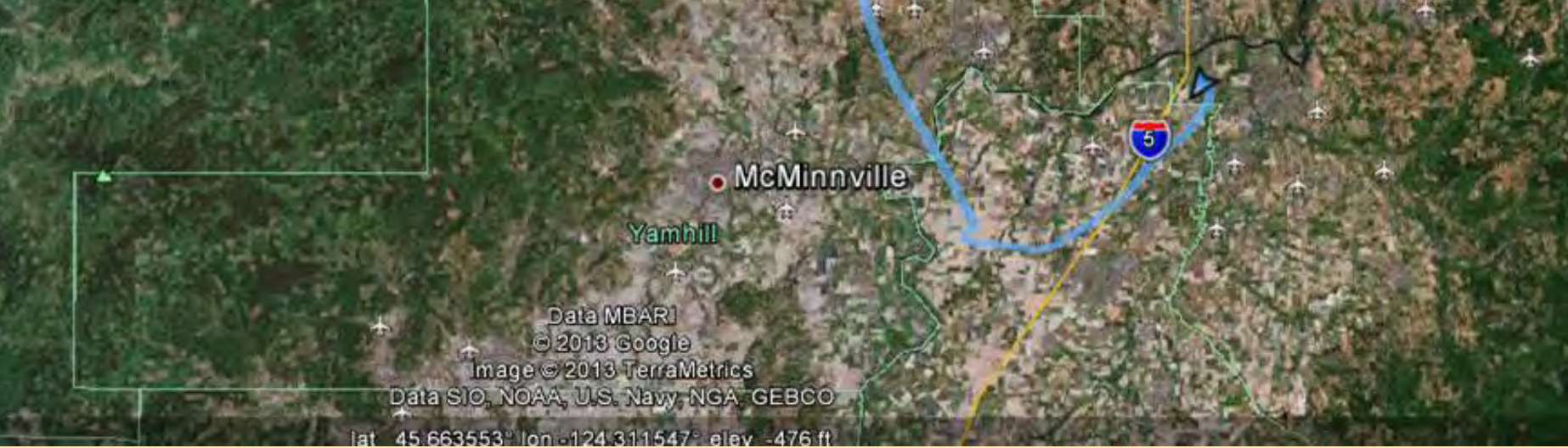




\section{NSC NBS -Lessons Learned}

- Successful demonstration of payload

- Terrain had a major impact on ability to track unit at launch and recovery sites

- Minimum temperature (courtesy of NSC): -20.6 degrees C

- Inside foam container

- Timing accuracy indicated no uncompensated clock drift

- Most data points fall within +/- 1us of UAT specs

- Emitter category 15 (space/trans-atmospheric vehicle) data is not smoothed resulting in "noisy" vertical rate information

- Exelis GBT systems currently filter out targets with a ground distance of 300 nautical miles from the receiver.

- Prevented an adequate analysis of achievable range 


\section{Up Aerospace SpaceLoft XL}

- Provider: Up Aerospace

- Vehicle: SpaceLoft XL Sounding Rocket

- Supported by NASA Flight Opportunities Program

- Milestones:

- MITRE UBR-TX ADS-B flights for SL-6 and SL-7 mission

- UBR-ERAU flight for SL-8 mission- November 2013

- Apogee: $384,100 \mathrm{ft}$. MSL

- Planned Flights

- SL-11

- SL-12

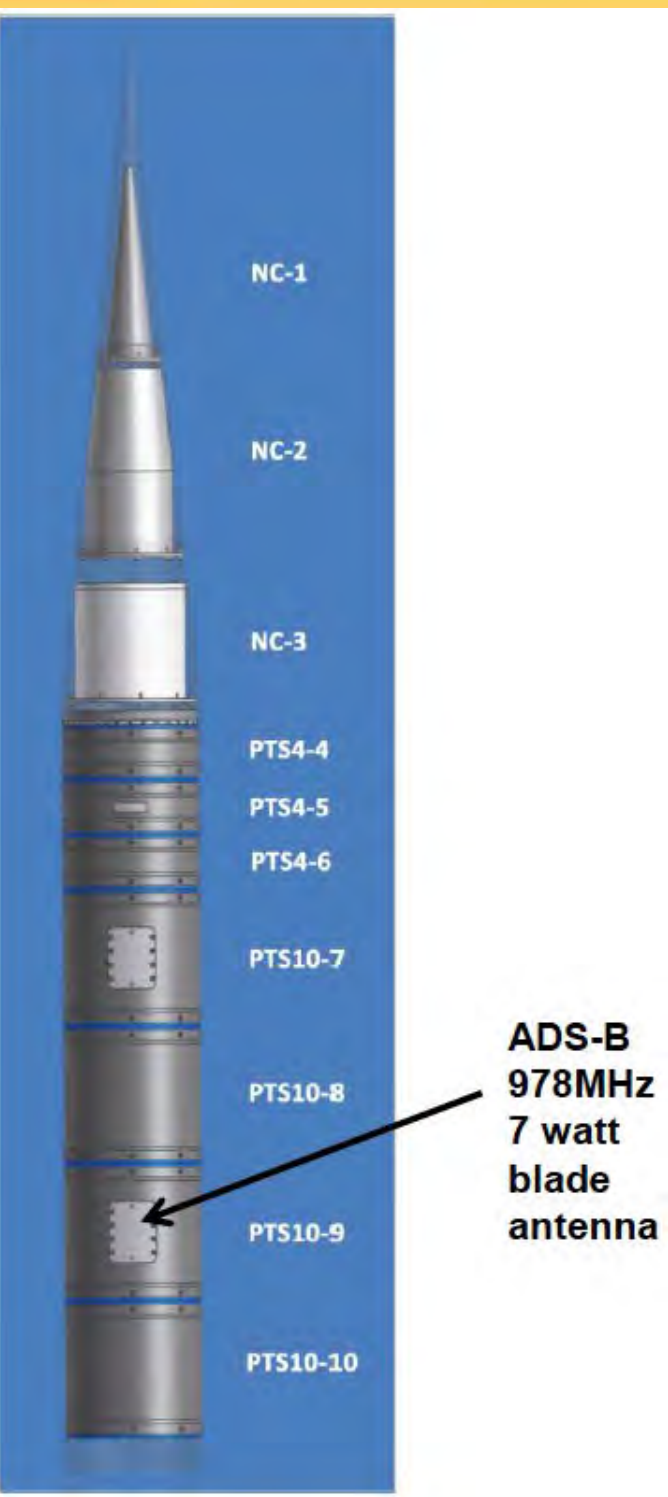


UP Aerospace SpaceLoft XL IntegratioA AMBronautical University FT S

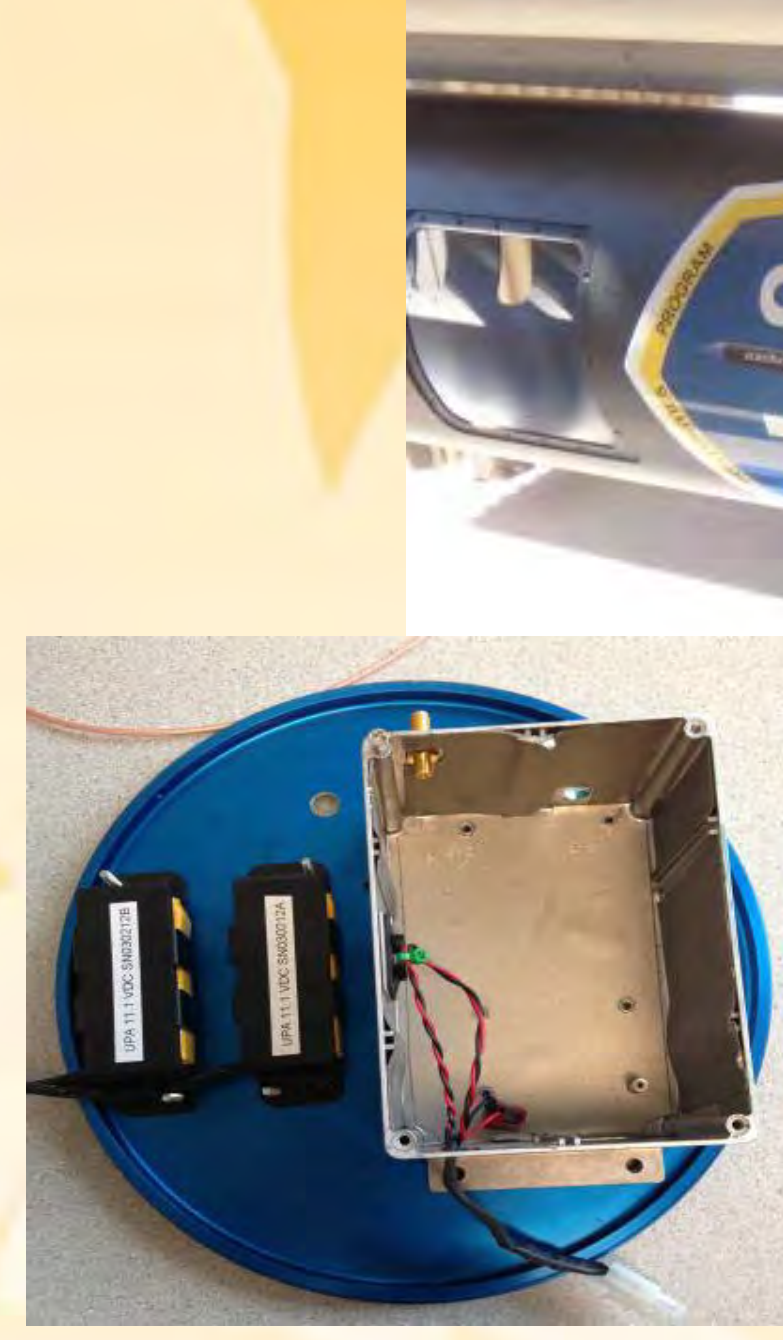




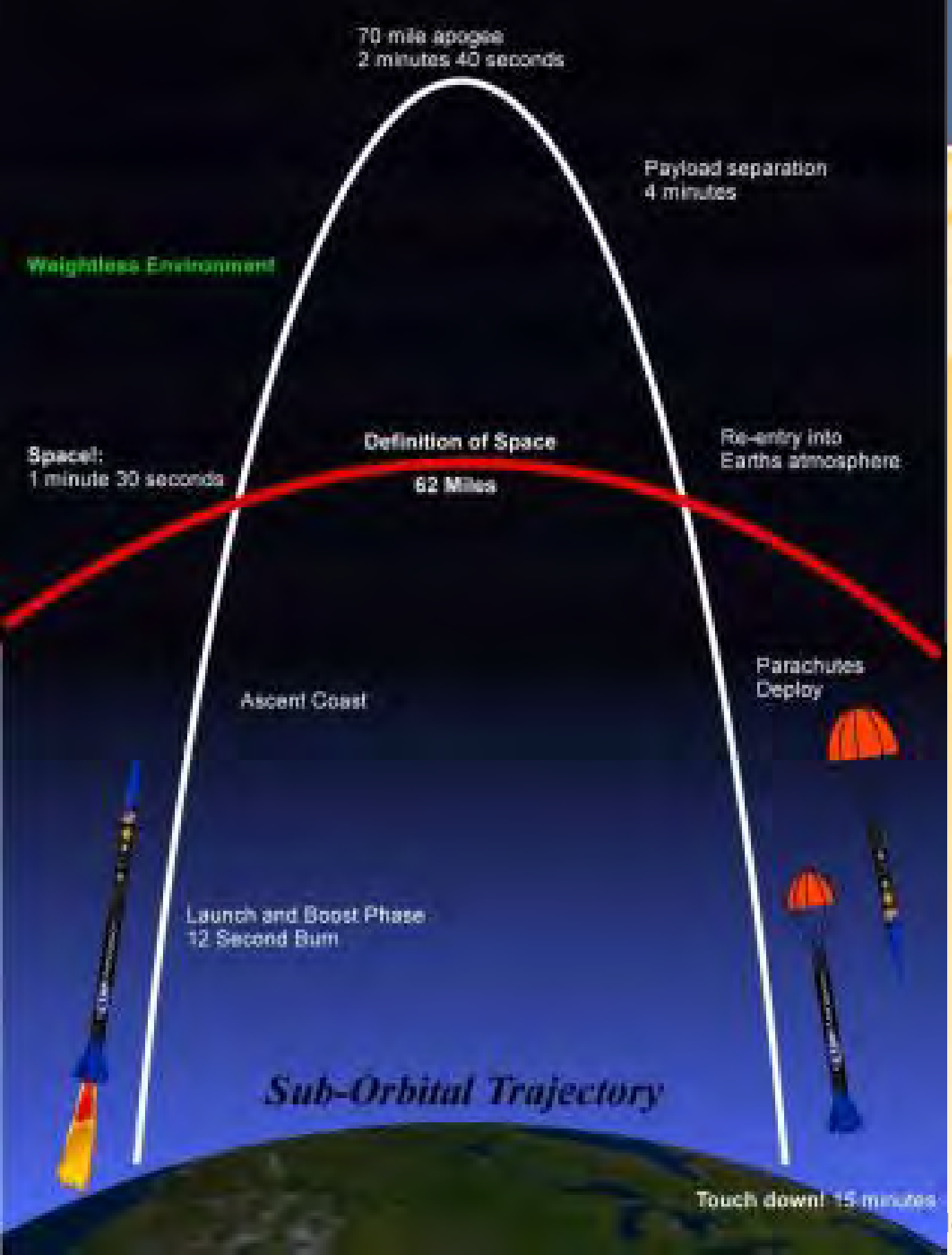

\section{EMBRYAIDDLE Aeronautical University}

\section{SL-8 Flight Profile}

\begin{tabular}{|l|l|}
\hline Event & $\begin{array}{l}\text { Time } \\
\text { (seconds) }\end{array}$ \\
\hline Launch & $\mathrm{T}+0$ \\
\hline Despin initiated & $\mathrm{T}+55$ \\
\hline Apogee (384,100 ft.) & $\mathrm{T}+162$ \\
\hline Payload separation & $\mathrm{T}+240$ \\
\hline Drogue deployment & $\mathrm{T}+442$ \\
\hline Chute Deployment & $\mathrm{T}+452$ \\
\hline Touchdown & $\mathrm{T}+751$ \\
\hline
\end{tabular}




\section{SL-8 Flight Analysis}

\begin{tabular}{|c|c|c|}
\hline Phase of flight & Metric & Result \\
\hline Full flight & $\%$ tracked by ADS-B & $73.8 \%$ \\
\hline \multirow{8}{*}{$\begin{array}{l}\text { Launch to } T+62 \\
\text { ( } 7 \text { seconds post- } \\
\text { despin initiation) }\end{array}$} & $\%$ of flight tracked by ADS-B & 80.5 \\
\hline & Avg. time between message & $1.27 \mathrm{~s}$ \\
\hline & Max. time between message & $8.00 \mathrm{~s}$ \\
\hline & $\begin{array}{l}\text { Max receivers tracking } \\
\text { (Ground-based Transceivers GBTs only) }\end{array}$ & 8 \\
\hline & Max receivers tracking (GBTs and portable) & 10 \\
\hline & Avg. latitude error & $16.145 \mathrm{E}-05 \mathrm{deg}$. \\
\hline & Avg. longitude error & $9.170 \mathrm{E}-05 \mathrm{deg}$. \\
\hline & Avg. altitude error (below 101,350 ft.) & $54.31 \mathrm{ft}$. \\
\hline \multirow{3}{*}{$\begin{array}{l}\text { Post T+315 } \\
\text { (descent and } \\
\text { deceleration to } \\
\text { less than } 1000 \\
\mathrm{ft} . / \mathrm{sec} \text { ) }\end{array}$} & $\%$ of flight tracked by ADS-B & $95.9 \%$ \\
\hline & Avg. time between message & $1.04 \mathrm{~s}$ \\
\hline & Max. time between message & $3.00 \mathrm{~s}$ \\
\hline
\end{tabular}

\section{EMBRYRIDDLE Aeronautical University}

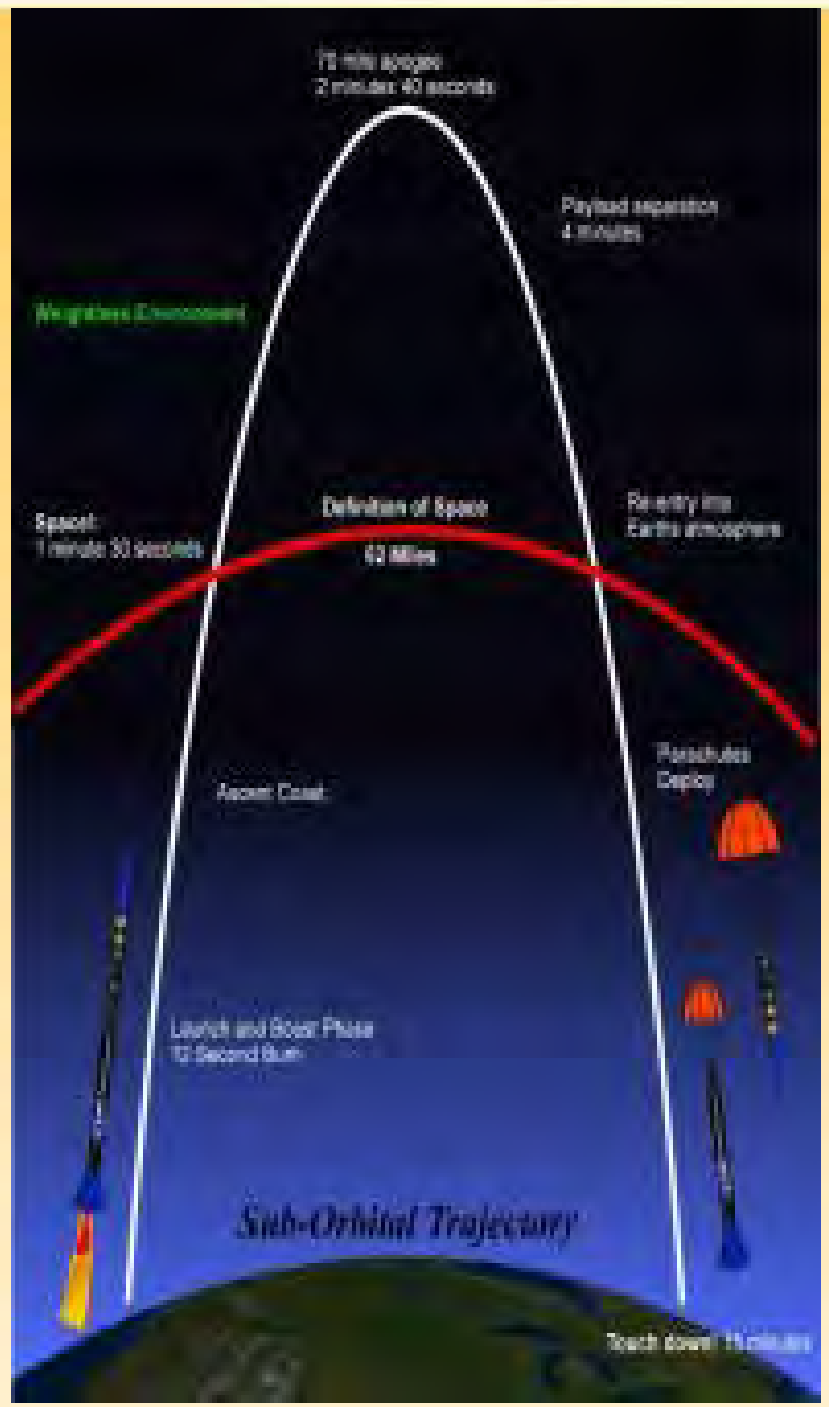

Apogee: $384,100 \mathrm{ft} . \mathrm{MSL}$ 


\section{SL-8 Performance vs. Success Criteria}

\begin{tabular}{|l|l|l|}
\hline Criteria & Pass / Fail & Comments \\
\hline $\begin{array}{l}\text { Broadcasts well-formed } \\
\text { messages }\end{array}$ & Pass & $\begin{array}{l}\text { GBTs and two portable Garmin GDL 90 } \\
\text { successfully parsed data }\end{array}$ \\
\hline $\begin{array}{l}\text { Vehicle tracking for 90\% of } \\
\text { flight }\end{array}$ & Fail & $\begin{array}{l}73.8 \% \text { of full flight, 80.5\% post-despin, and } \\
95.9 \% \text { on descent. }\end{array}$ \\
\hline Characterization of data loss & Pass & $\begin{array}{l}\text { Primary characterization of data loss was } \\
\text { configuration onboard spacecraft and NOT } \\
\text { ADS-B unit itself. }\end{array}$ \\
\hline $\begin{array}{l}\text { Correlated with other data } \\
\text { sources }\end{array}$ & Pass & $\begin{array}{l}\text { Utilized truth data from WSMR primary radar. } \\
\text { Position/altitude accuracy measured. }\end{array}$ \\
\hline
\end{tabular}


- Two prior flights with "basic" MITRE ADS-B payload minimized risk of vehicle integration and site support

- Payload demonstrated to be viable for tracking sub-orbital RLV or sounding rocket of this velocity, altitude and range

- Additional transmit antennas and transmission power desirable for longer range, higher altitude flights

- Single transmit antenna briefly blocked by rocket body at apogee

- Current GPS antenna and amplifier may not be sufficient to maintain lock through all phases of flight

- Desirable for future missions to have onboard inertial measurement unit with payload and/or telemetry to correlate with data received (future SL missions will have telemetry)

- Desirable to equip future vehicles that host payload with GPS translator (s)

- record raw GPS data for post-flight analysis / truth data 


\section{Terminal Velocity Aerospace}

\section{=MBRYRIDDLE Aeronautical University}

- Partner: Terminal Velocity Aerospace

- Vehicle: RED-4U Reentry Vehicle

- Provider: Near Space Corporation

- Integration of Advanced ADS-B Unit onboard prototype reentry vehicle

- Funded by NASA Ames

- Proof-of-concept flight onboard high-altitude balloon

- Goals:

- Evaluate performance of ADS-B broadcasting through experimental TPS material

- Demonstration of UBR on new vehicle type

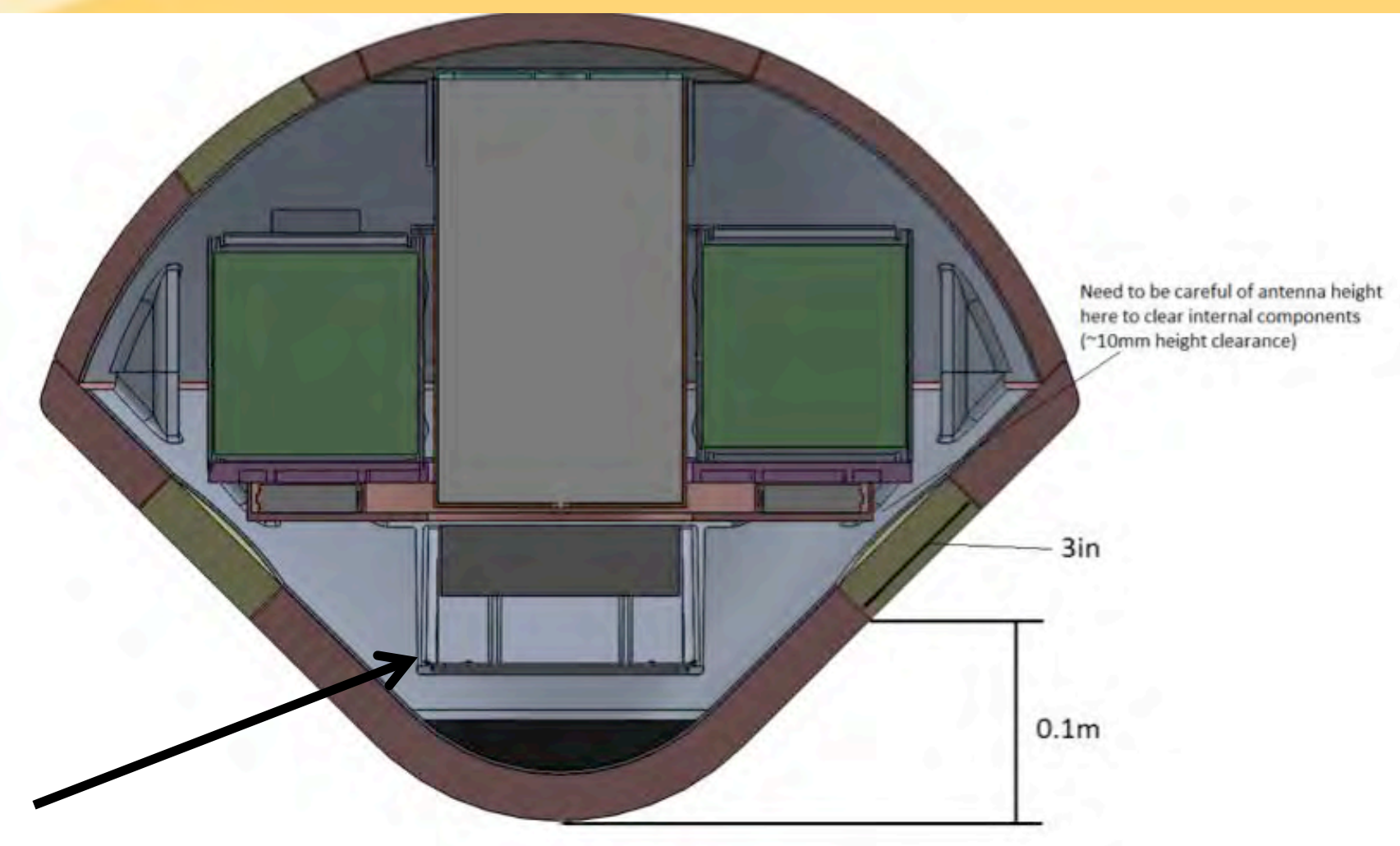




\section{Antenna Options}

- Antenna Selection and RF Analysis

- Limited space for antennas

- Aluminum foreshell with windows for UAT and GPS antennas

- Experimental RF transparent thermal protection system substrate for windows

- NASA Ames

- Material or its RF characteristics not available

- Option \#1: Antcom off-the-shelf patch antenna tuned to $978 \mathrm{MHz}$

- Less costly

- Faster turn around time

- Option \#2: Custom patch antenna

- Designed and tuned to RF environment of the spacecraft and the TPS materials

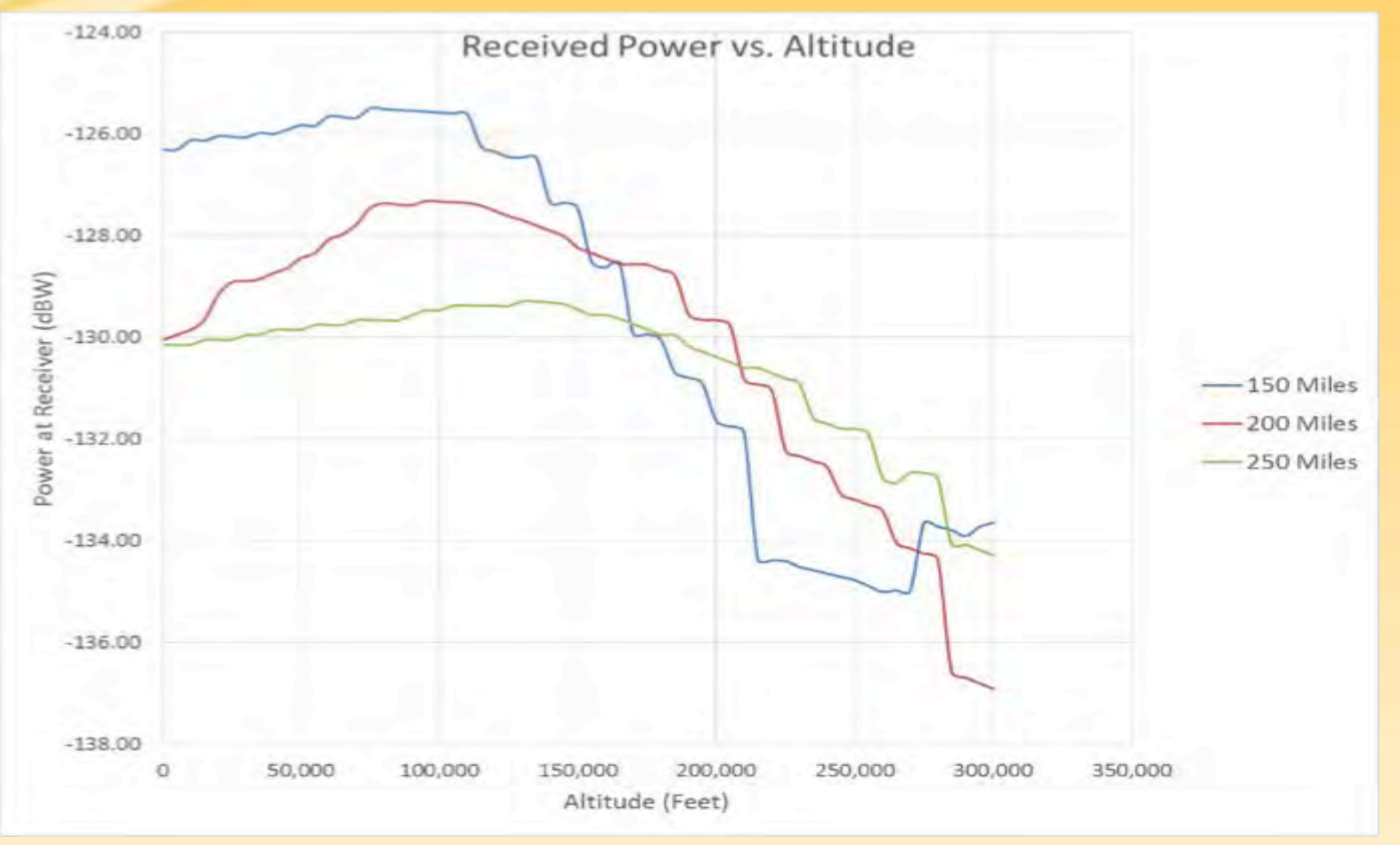

- Option \#1 was selected given budget, scope, and time 
Terminal Velocity Aerospace Reentry Vehicle Drop from stratospheric balloon
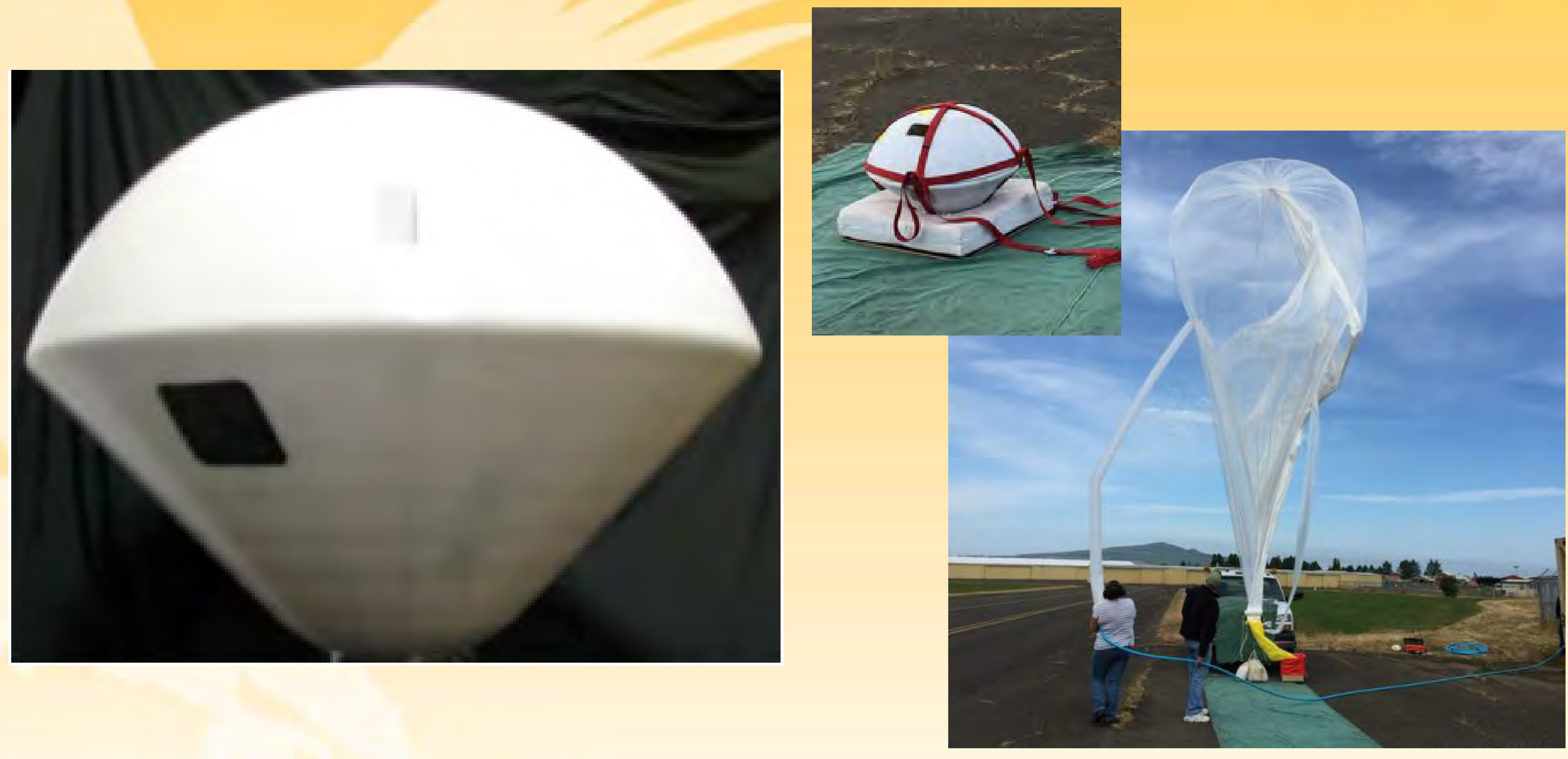


\section{System Integration Ground Test}

- Performed by ANG-33 Surveillance Branch, Engineering Development Services Development from FAA WJH Technical Center

- Location: Oregon, May 2015

- Near Space Corporation Facility

- Integration with stratospheric balloon

- UBR-ERAU (ERAU0002) onboard balloon gondola

- UBR-ERAU (ERAU0005) onboard TVA RED-4U

- Hoisted by crane to replicate flight configuration

- Data received by portable Garmin GDL-88 


\section{Flight Test June 21, 2015}

ERAU0005 Altitude (ft) and Velocity (ft/min) Profiles vs. Time (s)

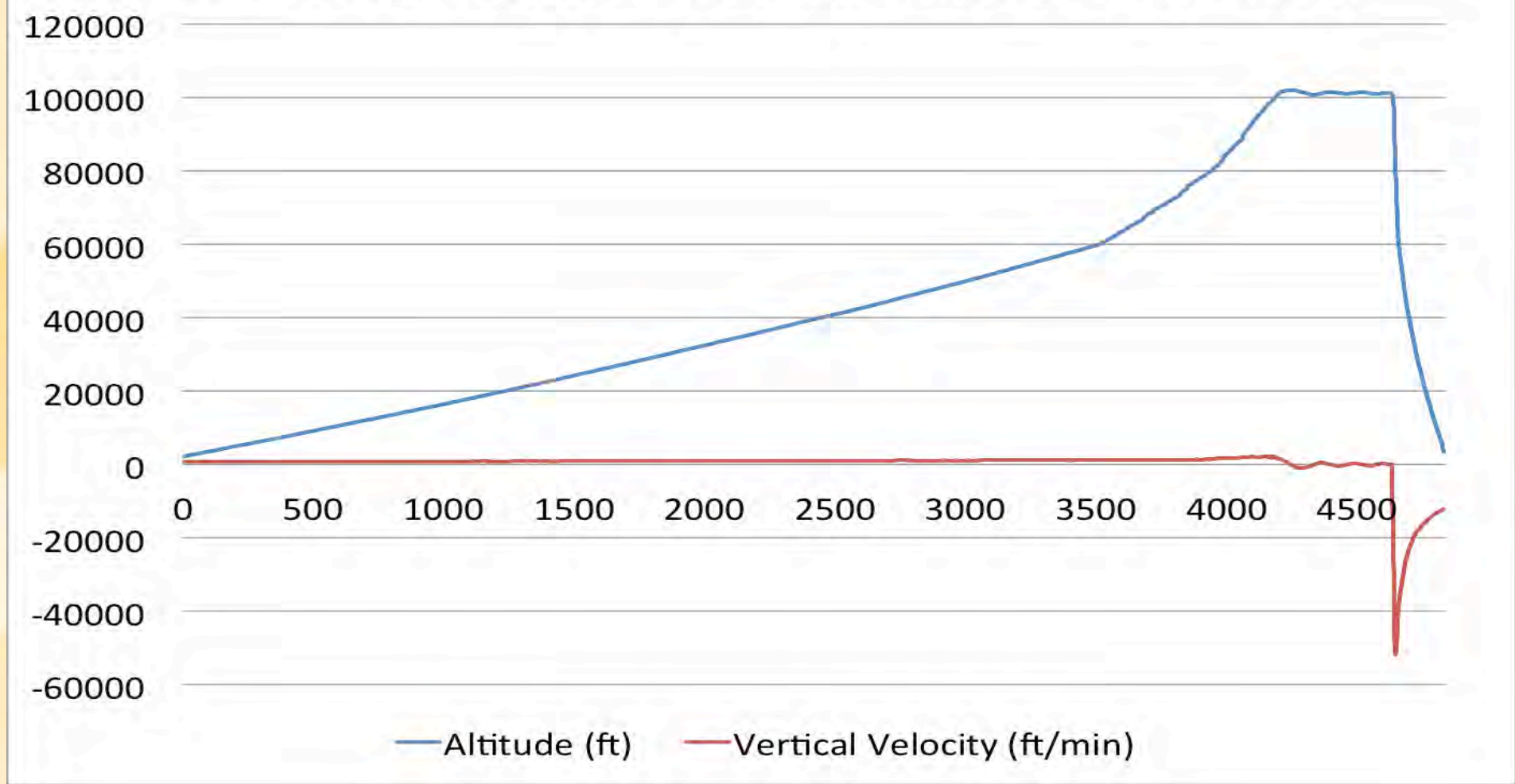




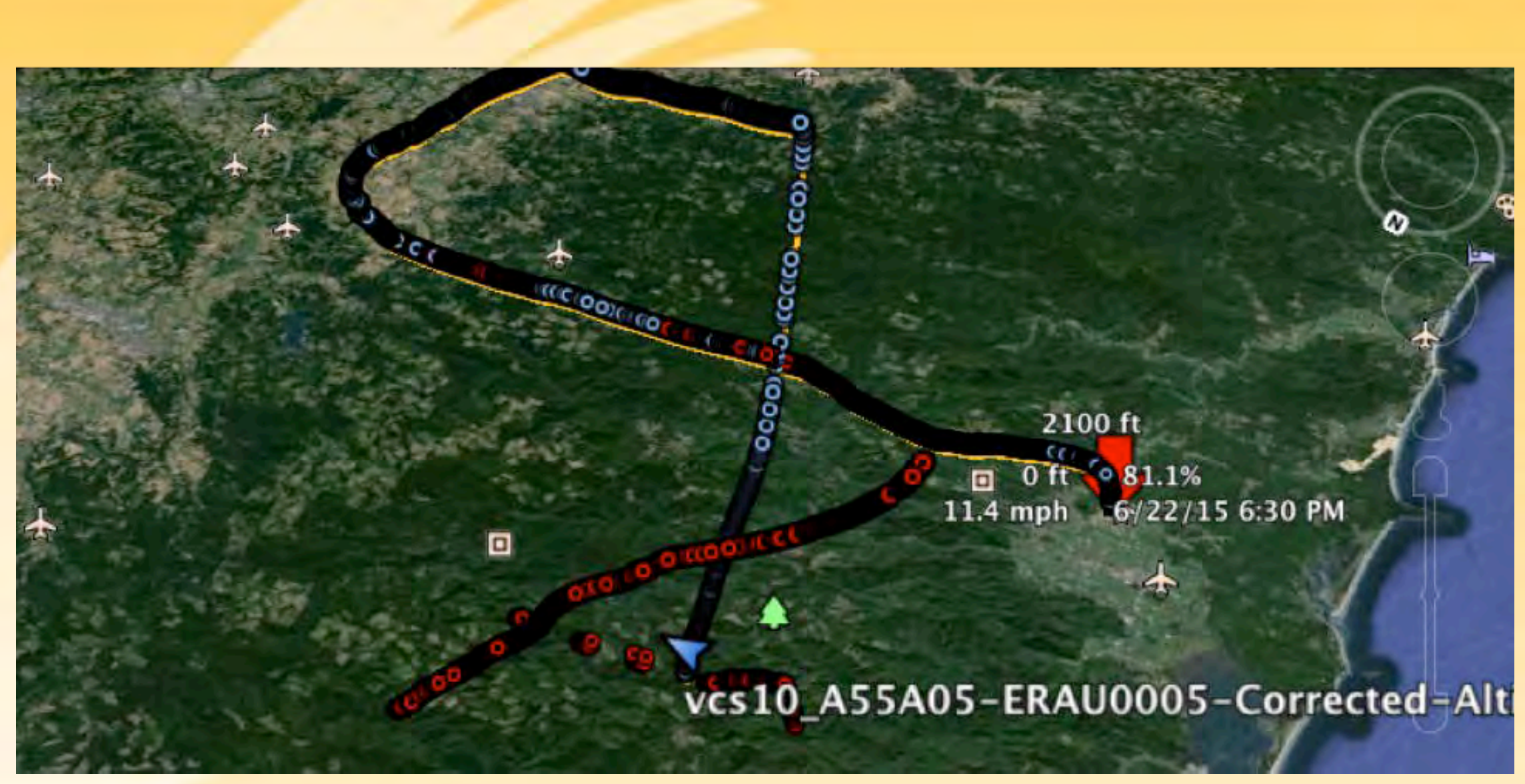

TVA RED-4U provided opportunity to operate two ADS-B payloads simultaneously. One tracked gondola while other tracked RED-4U spacecraft 
- ERAU0005 performed well throughout flight onboard RED-4U

- RED-4U parachute did not deploy

- Tracked ERAU0005 along ballistic descent trajectory

- Exceeded maximum climb/descent rate of UAT standard and "rolled-over"

- ERAU0005 was total loss

- ERAU0002 on gondola lost GPS lock for part of

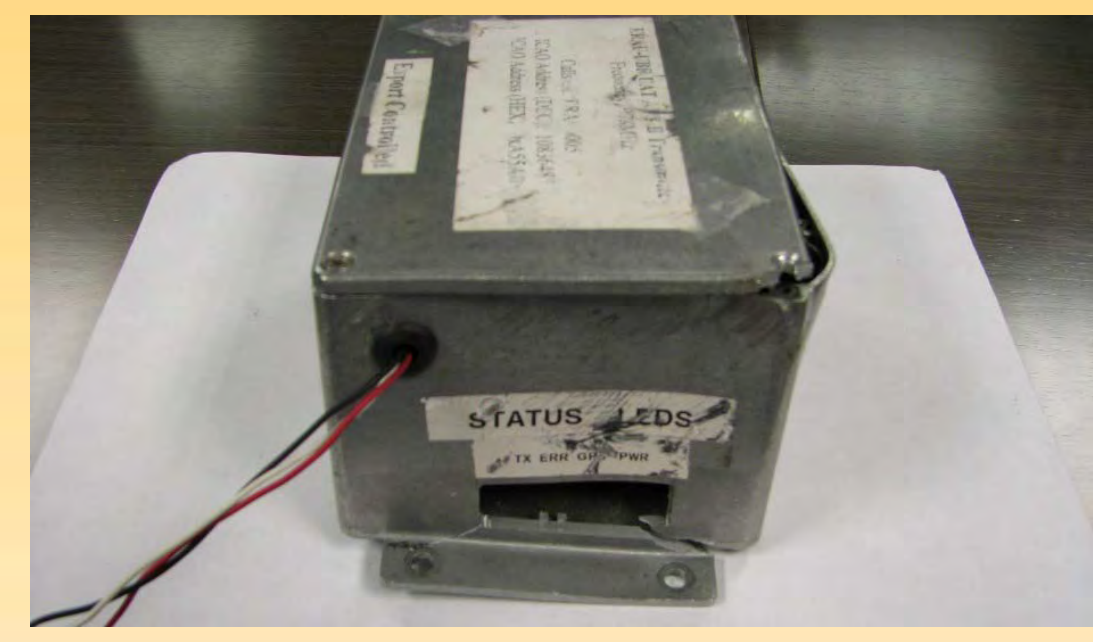
ascent due to faulty connector.

- Connector damaged during Near Space Corporation High Altitude Shuttle System flight (rough landing)

- Regained during descent under parachute.

- ERAU0002 payload has been replaced for all future use 


\section{EMBRYRIDDLE Aeronautical University}

\section{Path Forward}

- Future upgrades

- Future Flights 


\section{Proposed Future Upgrades}

- Dual antenna configuration

- UBR-TX design supported only one antenna

- Payload hardening and size reduction

- Unit designed as a proof-of-concept, but further hardening of payload needed for wider use in space applications

- Payload size is a limiting factor for finding suitable test platforms

- Increase output rate of ADS-B message

- Power amplification to support future use in LEO flight opportunities

- Doppler shift impact and mitigation

- RF modeling and radio tuning need to be investigated

- Reduce system startup time

- Reduce 15-30 second startup time 


\section{Future Flights}

- Near Space Corporation's High Altitude Shuttle System

- Surrogate winged suborbital vehicle performing a descent into NAS (from above 60, 000 feet)

- Up Aerospace SL-11 and SL-12

- TBD 2018

- New GPS antenna and IMU to log vehicle acceleration and orientation

- Coordination with NASA FOP and other flight providers for future flights

- Future announcements pending 


\section{Summary}

- ADS-B provides a suitable means for the real-time tracking of commercial space vehicles to mitigate the impact to routine operations within the National Airspace System

- MITRE UBR-TX provided a sufficient platform to evaluate this opportunity through upgrades to hardware and software

- Flight demonstration has provided

- Opportunities to further develop and refine payload

- Address payload integration issues across flight providers

- Receive input from future users (i.e. flight providers) 


\section{Questions}

- Any questions? 